\title{
BDA warns of exodus from service, as access crisis deepens
}

The British Dental Association (BDA) has urged government to set out a clear route map for reform and relaxation of COVID restrictions, as new survey data point to an exodus from the service as the access crisis continues with nearly 30 million appointments lost since the first lockdown.

According to a new survey of dentists in England:

- Nearly half ( $47 \%)$ of dentists indicate they are now likely to change career or seek early retirement in the next 12 months should current COVID restrictions remain in place. The same proportion state they are likely to reduce their NHS commitment

- Working in high level PPE mandated under current infection control procedures is having a devastating impact on dentists' morale, with nearly nine in ten $(88 \%)$ indicating it is having a high impact on their morale. Seventy-eight percent cite financial uncertainty as having a high impact, and their inability to provide pre-COVID levels of care. Two thirds cite hitting NHS targets imposed by the government on 1 January 2021. Since the new year, the workforce report the highest levels of stress compared to any point since the onset of the pandemic

- Nearly two thirds of NHS dentists estimate they will not meet controversial imposed targets, where they will face penalties for not hitting $60 \%$ of pre-COVID activity levels. Those that have made progress have done so unsustainably. Sixtytwo percent say their practice had to invest in new ventilation equipment, without any government support; $41 \%$ say they were forced to refocus on routine over urgent appointments, with similar numbers saying they have reduced private work, or reduced or eliminated annual leave

- England remains the only UK nation where government has not committed to or embarked on exploratory work to provide capital funding for ventilation systems to enable practices to increase patient numbers while keeping to infection control restrictions. While securing new kit has been the number one strategy deployed by dentists to meet
NHS activity targets, nearly $70 \%$ of practices say they now face financial barriers to further investment

- Nearly half of dentists (47\%) lack confidence in terms of the business outlook for their practice should current standard operating procedures remain unchanged.

BDA analysis of Freedom of Information data indicates that nearly $70 \%$ of appointments - or 28 million courses of treatment that would have been delivered in NHS services in England in the year from March 2020 have been missed. The BDA estimates by now the figure is likely to have exceeded 30 million. While numbers have increased, MPs had expressed concern in January that the current interim system of targets would 'prioritise volume over need' and indeed urgent treatment delivered has fallen since the new year.

While dentist leaders have welcomed recent government commitments to reform the widely discredited activity-based contract at the heart of NHS dentistry, they have warned needed change could be fatally undermined by further reductions in capacity through colleagues leaving the service or reducing their NHS commitment. The BDA believe contractual and legislative change needs to be in place before 1 April 2022, the beginning of the next NHS financial year.

With the vaccination programme making real headway the BDA has also underlined the need for a clear timetable for revising high intensity infection prevention and control procedures including heavy duty PPE and maintaining lengthy gaps between appointments - given the huge impact on both productivity and the workforce.

MPs were set to tackle these issues in a Back Bench Business debate led by Bedford MP Mohammad Yasin on 25 May 2021.

Shawn Charlwood, Chair of the British Dental Association's General Dental Practice Committee said: 'Fixing NHS dentistry will be impossible if dentists are left unwilling to work in it. We need a clear road map that lifts restrictions, provides needed support to all practices and makes a decisive break with a broken contract'.

\section{Healthwatch England report reveals concerns around dental access}

Healthwatch England has published a report ${ }^{1}$ on dentistry during the COVID-19 pandemic, revealing concerns around levels of access, which has been picked up in the national media.

The findings indicated that, between January and March 2021:

- $80 \%$ of people found it difficult to access timely care

- $59 \%$ reported a negative experience of care

- $3 \%$ reported a positive experience.

Reported problems concerning NHS dentistry included delayed and unequal access, disrupted care, pressure to go private, being left in pain and provision of poor information. Responding to the findings, Healthwatch has called for action in four areas:
1. A more rapid and radical reform of the way dentistry is commissioned and provided

2. Using the reform of commissioning to tackle the twin crises of access and affordability

3. Greater clarity in the information about NHS dentistry

4. Look at using dental practices to support people's general health.

\section{Reference}

1. Healthwatch. Dentistry during COVID-19 insight briefing. 24 May 2021. Available at: https://www.healthwatch.co.uk/report/2021-05-24/dentistry-during-covid-19insight-briefing (accessed 28 May 2021). 